
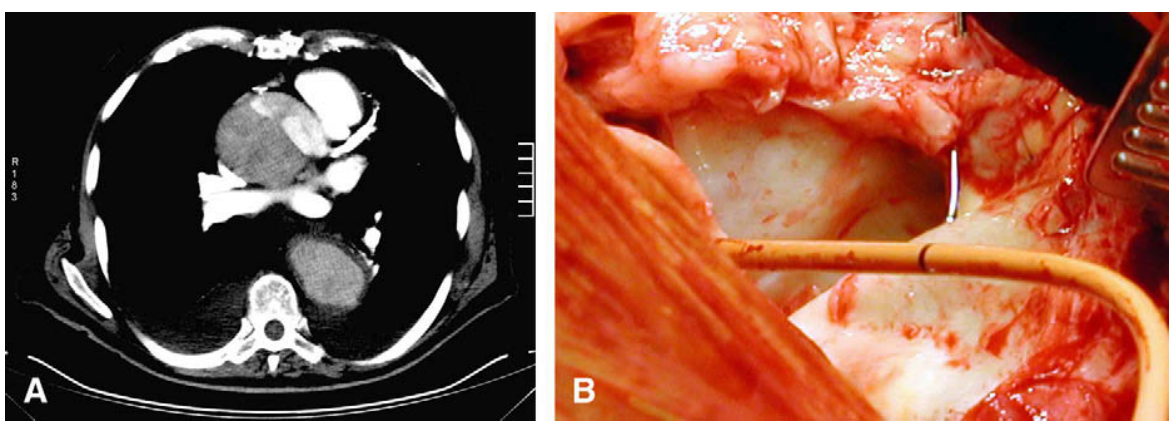

FIGURE 1. A, Aortic dissection with entry arising from proximal bypass anastomosis on 6-month postoperative computed tomographic scan. B, Intraoperative finding; metal probe shows immediate connection between proximal anastomosis of radial artery and entry tear of dissection.

TABLE 1. Neurologic outcomes of patients undergoing off-pump cardiopulmonary bypass grafting with Heartstring* device for construction of the proximal aortic anastomoses

\begin{tabular}{lcc}
\hline & Mar-Dec 2003 & Jan-Dec 2004 \\
\hline No. of patients & 189 & 256 \\
Proximal anastomoses (No.) & 333 & 451 \\
Neurologic events (\%) & $1 \%$ & $0 \%$ \\
\hline
\end{tabular}

*Guidant Corporation, Indianapolis, Ind.

have been able to reduce neurologic complications (Table 1). This device selectively addresses the question of clampless revascularization without adding new problems derived from the anastomosis technique, which seems to be the drawback of several automatic proximal anastomosis devices currently in development. ${ }^{5}$

In conclusion, this report underlines further the need for long-term follow-up of patients in whom new devices for proximal anastomoses are used, to check for the potential development of late aortic dissection. In addition, it emphasizes the importance of identifying predisposing factors that might help in selecting appropriate patients for the application of such devices.

\section{References}

1. Stanger O, Oberwalder P, Dacar D, Knez I, Rigler B. Late dissection of the ascending aorta after previous cardiac surgery: risk, presentation and outcome. Eur J Cardiothorac Surg. 2002;21:453-8.

2. Boruchow IB, Iyengar R, Jude JR. Injury to ascending aorta by partial-occlusion clamp during aorta-coronary bypass. J Thorac Cardiovasc Surg. 1977;73:303-5.

3. Tavakoli R, Reuthebuch O, Hofer C, Grüenenfelder J, Genoni M. Off-pump coronary bypass grafting: the Zurich experience. Heart Surg Forum. 2005;8:E246-8.

4. Chavanon O, Carrier M, Cartier R, Hebert Y, Pellerin M, Page P, et al. Increased incidence of acute ascending aortic dissection with off-pump aortocoronary bypass surgery? Ann Thorac Surg. 2001;71:117-21.

5. Reuthebuch O, Kadner A, Lachat M, Kuenzli A, Schurr U, Turina M. Early bypass occlusion after deployment of nitinol connector devices. $J$ Thorac Cardiovasc Surg. 2004;127:1-6.

\title{
Sclerosing hemangioma with an air halo
}

Jung-Jyh Hung, MD, ${ }^{\text {a,b,c }}$ Jung-Sen Liu, MD, PhD, ${ }^{\mathrm{b}}$ and Wen-Hu Hsu, MD, ${ }^{\mathrm{c}}$ Taipei, Taiwan

Sclerosing hemangioma (SH), an unusual benign pulmonary neoplasm, was first described by Liebow and Hubbell ${ }^{1}$ in 1956. It occurs predominantly in middle-aged women. ${ }^{2}$ Most patients have no symptoms, with the tumors being de-

\footnotetext{
From the Institute of Clinical Medicine, National Yang-Ming University, ${ }^{\text {a the Depart- }}$ ment of Surgery, Cathay General Hospital, and School of Medicine, Fu Jen Catholic University, ${ }^{b}$ and the Division of Thoracic Surgery, Department of Surgery, Taipei Veterans General Hospital and School of Medicine, National Yang-Ming University, ${ }^{\mathrm{c}}$ Taipei, Taiwan.

Received for publication July 21, 2007; revisions received Aug 24, 2007; accepted for publication Nov 20, 2007

Address for reprints: Wen-Hu Hsu, MD, Division of Thoracic Surgery, Department of Surgery, Taipei Veterans General Hospital, No. 201, Section 2, Shih-Pai Rd, Taipei 112, Taiwan (E-mail: whhsu@vghtpe.gov.tw).

J Thorac Cardiovasc Surg 2008;136:1365-7

$0022-5223 / \$ 34.00$

Copyright (c) 2008 by The American Association for Thoracic Surgery

doi:10.1016/j.jtcvs.2007.11.073
}

tected incidentally during routine chest radiographic examination. Although SH is usually seen as a solitary peripheral nodule less than $3 \mathrm{~cm}$ in diameter, multiple lesions have been reported in as many as $4 \%$ of all cases. ${ }^{2}$ The characteristic radiologic feature of $\mathrm{SH}$ is a well-defined nodule with good enhancement. We present the case of a patient with SH with an unusual air halo.

\section{CLINICAL SUMMARY}

A symptom-free 23-year-old man came to our clinic because of an abnormal shadow found on a chest radiographic film during military physical check-up. He reported unremarkable family and medical histories. Physical examination revealed no abnormal physical findings. Laboratory data were normal, including normal carcinoembryonic antigen 


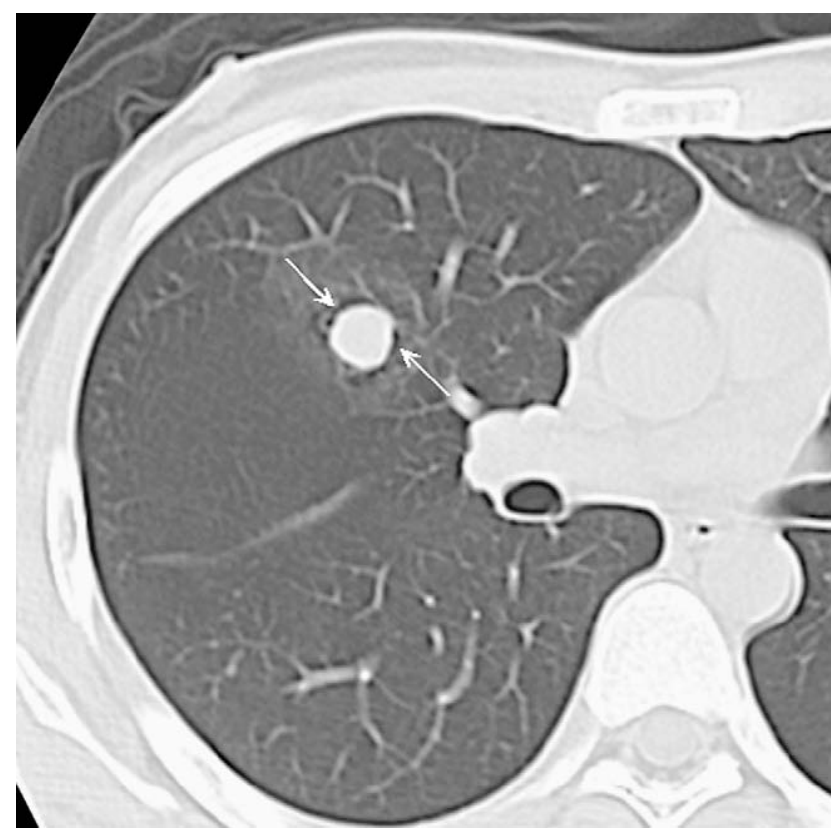

FIGURE 1. Chest computed tomographic scan demonstrating emphysematous change in pulmonary parenchyma surrounding nodule (arrows).

and squamous cell carcinoma antigen levels. Computed tomography of the chest demonstrated a well-defined nodule $(2.5 \times 1.5 \times 1.5 \mathrm{~cm})$ in the anterior segment of the right upper lobe of the lung with moderate enhancement after injection of contrast agent. Emphysematous change in the pulmonary parenchyma surrounding the nodule was revealed under the setting of lung window (Figure 1). Magnetic resonance imaging of the chest revealed a well-defined, round nodule $(2.3 \times 1.7 \times 1.7 \mathrm{~cm})$ in the right upper lobe of the lung with higher T1- and T2-weighted signal intensities than seen in the adjacent muscles and mild enhancement after contrast injection. An air halo around the nodule was also identified (Figure 2). Bronchoscopy demonstrated no abnormality within visible range. Whole-body bone scan showed no evidence of metastasis. Surgical intervention was performed through a right posterolateral thoracotomy. Intraoperatively, a $2.5 \times 1.5 \times 1.5 \mathrm{~cm}$, macroscopically grayish, soft mass was found. Wedge resection of the nodule was done. Because of much mucoid substances and nuclear atypia, a frozen-section diagnosis of non-small cell lung cancer was made and lobectomy of the right upper lobe with radical lymph node dissection was performed. Pathologic examination of permanent sections revealed pulmonary SH.

\section{DISCUSSION}

$\mathrm{SH}$, a benign pulmonary neoplasm, occurs predominantly in middle-aged women. ${ }^{1,2} \mathrm{SH}$ is composed of four major histologic patterns: papillary, solid, hemorrhagic, and scle-

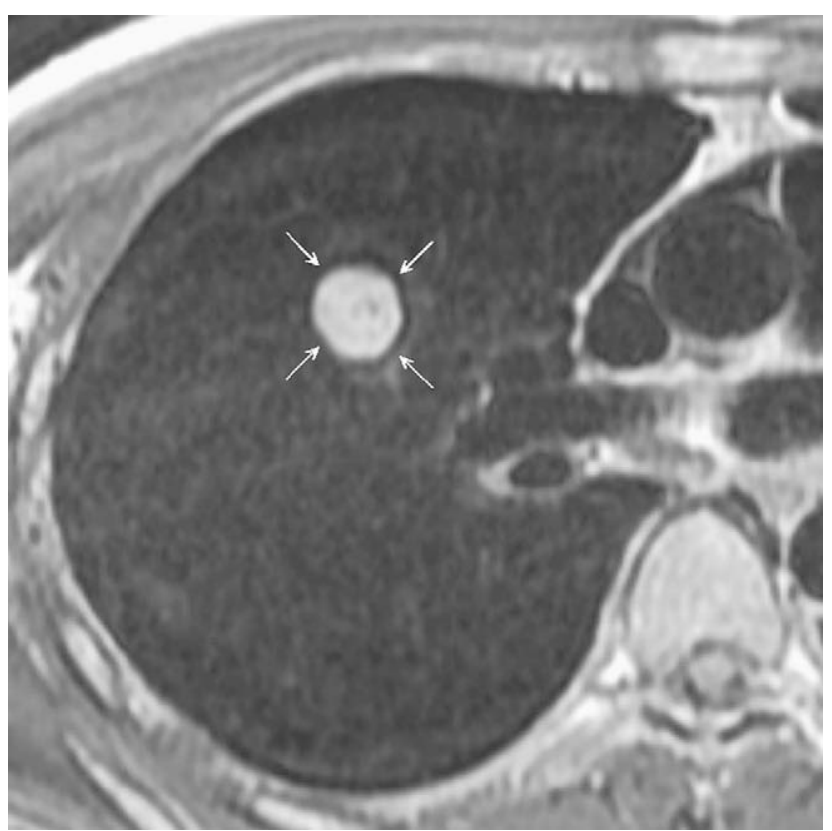

FIGURE 2. Magnetic resonance imaging of chest revealing air halo surrounding nodule (arrows).

rotic. In one large series, a papillary pattern was observed in most cases of $\mathrm{SH}$, and this tends to be the predominant type. Recent studies suggest that $\mathrm{SH}$ is derived from primitive respiratory epithelium. ${ }^{2}$ Although $\mathrm{SH}$ is considered a benign tumor, mediastinal lymph node metastasis has been noted in several case reports.

The characteristic radiologic feature of $\mathrm{SH}$ is a welldefined nodule with good enhancement. Air meniscus sign, most commonly seen in aspergilloma, is uncommon but specific to $\mathrm{SH}$. Bahk and colleagues ${ }^{3}$ first described air-meniscus sign in a case of $\mathrm{SH}$ in 1978. Several cases of SH surrounded by air spaces have also been reported. Proliferation and hyalinization of undifferentiated alveolar mesenchymal cells may wrap around the bronchus and cause distention of the distal air space. ${ }^{3}$ Peritumoral hemorrhage and tumor contraction, followed by communication of the airway, may be another mechanism for development of air meniscus sign. ${ }^{3}$ Nam and associates ${ }^{4}$ have suggested that air meniscus sign, although an uncommon finding, is helpful in the differential diagnosis of $\mathrm{SH}$ from other benign tumors. Magnetic resonance imaging of the chest demonstrating an air halo surrounding SH has not previously been reported in the literature.

The treatment of choice for $\mathrm{SH}$ is limited resection. The long-term survival after complete surgical resection is excellent. ${ }^{2}$ Preoperative cytologic study is often insufficient for diagnosis of SH. It may be also difficult to establish a definitive diagnosis by intraoperative frozen-section. Some reports have suggested that it is difficult to differentiate $\mathrm{SH}$ from bronchoalveolar cell carcinoma or metastatic papillary 
adenocarcinoma. ${ }^{5}$ Expressions of thyroid transcription factor 1 and epithelial membrane antigen in round and surface cells of SH, accompanied by negative results of round cells for pancytokeratin, provide useful clues for the diagnosis of $\mathrm{SH}^{2}$ Further studies are needed to elucidate the histogenesis and biologic behavior to aid in the diagnosis of SH. In our case, a false frozen-section diagnosis of non-small cell lung cancer was made because of the presence of copious mucoid substances and nuclear atypia. Lobectomy of the right upper lobe with radical lymph node dissection was therefore performed. Pathologic examination of permanent sections revealed pulmonary $\mathrm{SH}$.

The characteristic computed tomographic and magnetic resonance imaging features of SH may help with preoperative diagnosis and assessment.
We are grateful to Dr Li Wing-Yin for his assistance with the pathologic diagnosis. We also thank Dr Wen-Juei Jeng for her contribution to this article.

\section{References}

1. Liebow AA, Hubbell DS. Sclerosing hemangioma (histiocytoma) of the lung. Cancer. 1956;9:53-75.

2. Devouassoux-Shisheboran M, Hayashi T, Linnoila RI, Koss MN, Travis WD. A clinicopathologic study of 100 cases of pulmonary sclerosing hemangioma with immunohistochemical studies: TTF-1 is expressed in both round and surface cells, suggesting an origin from primitive respiratory epithelium. Am J Surg Pathol. 2000;24:906-16.

3. Bahk YW, Shinn KS, Choi BS. The air meniscus sign in sclerosing hemangioma of the lung. Radiology. 1978;128:27-9.

4. Nam JE, Ryu YH, Cho SH, Lee YJ, Kim HJ, Lee DY, et al. Air-trapping zone surrounding sclerosing hemangioma of the lung. J Comput Assist Tomogr. 2002;26:358-61.

5. Wang SE, Nieberg RK. Fine needle aspiration cytology of sclerosing hemangioma of the lung, a mimicker of bronchioloalveolar carcinoma. Acta Cytol. 1986;30:51-4.

\title{
Long-term remission of hepatic hydrothorax after OK-432 pleurodesis
}

\author{
Pei-Ying Lin, MD, Ping-Hung Kuo, MD, Chong-Jen Yu, MD, PhD, and Pan-Chyr Yang, MD, PhD, Taipei, Taiwan
}

Hepatic hydrothorax, a manifestation of end-stage liver disease, is defined as the presence of more than $500 \mathrm{~mL}$ of pleural effusion in patients with liver cirrhosis who do not have cardiopulmonary diseases or malignancies that could explain this effusion. ${ }^{1}$ Strauss and Boyer ${ }^{2}$ have reported incidences of 85.4 right-sided, $12.5 \%$ left-sided, and $2 \%$ bilateral hepatic hydrothoraces. The most likely cause is fluid transfer from the abdomen to the pleural space through diaphragmatic defects. ${ }^{1}$ Optimal management remains unclear, and thoracocentesis is frequently required for immediate symptom relief. Alternative treatments, including pleurodesis by tube thoracostomy or video-assisted thoracoscopic surgery (VATS), diaphragm repair, transjugular intrahepatic portosystemic shunt, peritoneovenous shunts, or liver transplantation, should be considered when frequent therapeutic thoracocentesis is needed. ${ }^{1}$ We report here the first case of refractory hepatic hydrothorax in which a 5-year remission was achieved by nonsurgical OK-432 pleurodesis.

\footnotetext{
From the Division of Chest Medicine, Department of Internal Medicine, National Taiwan University Hospital, Taipei, Taiwan.

Received for publication Oct 15, 2007; accepted for publication Dec 2, 2007

Address for reprints: Ping-Hung Kuo, MD, Division of Chest Medicine, Department of Internal Medicine, National Taiwan University Hospital No. 7, Chung-Shan S

Rd, Taipei 100, Taiwan (E-mail: Kph712@ntuh.gov.tw).

J Thorac Cardiovasc Surg 2008;136:1367-9

$0022-5223 / \$ 34.00$

Copyright (c) 2008 by The American Association for Thoracic Surgery

doi:10.1016/j.jtcvs.2007.12.078
}

\section{CLINICAL SUMMARY}

A 78-year-old woman with hepatitis C-related ChildPugh class $\mathrm{C}$ liver cirrhosis came to our hospital with new-onset dyspnea and bilateral lower leg pitting edema. There was a history of refractory right-sided hepatic hydrothorax 5 years previously that was managed with OK-432 pleurodesis through a pigtail after failure of repeated minocycline pleurodesis. Surgical intervention was refused by the patient at that time because of older age and poor liver reserve. The patient had a 5-year symptomfree period with a regimen of oral diuretics and sodium restriction.

The physical examination revealed icteric sclera, right lower lung field dullness with decreased breath sound, and bilateral lower extremity pitting edema. The oxygen saturation was $82 \%$ on room air. Results of the neurologic examination were unremarkable. The hemogram was normal, whereas blood biochemistry studies revealed hyponatremia $(130 \mathrm{mmol} / \mathrm{L})$, hypoalbuminemia $(2.8 \mathrm{~g} / \mathrm{dL})$, and abnormal liver function (total bilirubin $3.5 \mathrm{mg} / \mathrm{dL}$, direct bilirubin $1.42 \mathrm{mg} / \mathrm{dL}$, aspartate aminotransferase 58 units/L, alanine aminotransferase $24 \mathrm{U} / \mathrm{L}$ ).

Chest radiography showed a large amount of right pleural effusion (Figure 1, A). Echocardiography revealed a good left ventricular ejection fraction. Chest computed tomographic scan disclosed right-sided pleural effusion with right lower lobe atelectasis, marked liver cirrhosis, esophageal 